\title{
Restoration of invaded Cape Floristic Region riparian systems leads to a recovery in foliage-active arthropod alpha- and beta-diversity
}

\author{
Malebajoa A. Maoela ${ }^{1,3,5}$, Francois Roets ${ }^{1,3}$, Shayne M. Jacobs ${ }^{1,4}$, and Karen J. Esler ${ }^{1,2,4}$
}

\begin{abstract}
${ }^{1}$ Department of Conservation Ecology and Entomology, Stellenbosch University, Private Bag X1, Matieland
\end{abstract} 7602, South Africa.

${ }^{2}$ DSTANRF Centre of Excellence for Invasion Biology, Stellenbosch University, Private Bag X1, Matieland 7602, South Africa.

${ }^{3}$ DSTANRF Centre of Excellence in Tree Health Biotechnology (CTHB), Forestry and Agricultural Biotechnology Institute (FABI), University of Pretoria, Private Bag X20, Hatfield, Pretoria, 0028, South Africa.

${ }^{4}$ Water Institute, Stellenbosch University, Private Bag X1, Stellenbosch, 7602, South Africa

${ }^{5}$ Address correspondence to Malebajoa A. Maoela, email address:malebajoam@gmail.com, telephone: $+27797253786$

\section{Acknowledgments}

Thanks to Marno Fourie and Oliver Kambaj for field assistance and reviewers for helpful suggestions to improve this manuscript. We thank private landowners and CapeNature for access to field sites (permit number: AAA008-00027-0028). This study was funded by the DST/NRF Centre of Excellence in Tree Health Biotechnology. Conflict of Interest: The authors declare that they have no conflict of interest.

\begin{abstract}
The Cape Floristic Region of South Africa is a global biodiversity hotspot threatened by invasive alien plants (IAPs). We assessed the effect of plant invasions, and their subsequent clearing, on riparian arthropod diversity. Foliage-active arthropod communities were collected from two native and one invasive alien tree species. Alpha- and beta- diversity of their associated arthropod communities were compared between near pristine, Acacia-invaded and restored sites. Arthropod alpha-diversity at near pristine sites was higher than at restored sites, and was lowest at invaded sites. This was true for most arthropod taxonomic groups associated with all native tree species and suggests a general trend towards recovery in arthropod alpha-diversity after IAP removal. Overall, arthropod species turnover among sites was significantly influenced by plant invasions with communities at near pristine sites having higher turnover than those at restored and invaded sites. This pattern was not evident at the level of individual tree species. Although arthropod community composition was significantly
\end{abstract}


influenced by plant invasions, only a few significant differences in arthropod community composition could be detected between restored and near pristine sites for all tree species and arthropod taxonomic groups. Assemblage composition on each tree species generally differed between sites with similar degrees of plant invasion indicating a strong turnover of arthropod communities across the landscape. Results further suggest that both arthropod alpha- and beta- diversity can recover after IAP removal, given sufficient time, but catchment signatures must be acknowledged when monitoring restoration recovery.

Keywords: Acacia mearnsii, Riparian zone, Invasive alien plants, Arthropod responses.

\section{Introduction}

Terrestrial arthropod populations and communities are associated with certain vegetation types, and the loss of suitable plant habitat can lead to their declines (Herrera and Dudley 2003; Longcore 2003). Among the primary threats to arthropod diversity are introductions of invasive species (Tallamy 2004; Magoba and Samways 2012). Dense stands of Invasive Alien Plants (IAPs) are a growing threat to native biodiversity and ecosystem functioning (Sala et al. 2000; Le Maitre et al. 2004; Clavero and Garciá-Berthou 2005; van Wilgen et al. 2008). They cause changes in vegetation structure, composition and host quality and therefore affect arthropod assemblages (Beerling and Dawah 1993). For example, Slobodchikoff and Doven (1977) showed that increased cover of the non-native grass Ammophilia arenaria disrupted the structure of sand dune arthropod communities in California. Similarly, abundance and composition in native ant and bird communities has been altered by IAPs in the Cape Floristic Region (CFR) of South Africa (French and Major 2001; Mokotjomela and Hoffmann 2013), with significant implications for the seed dispersal of native plants (Mokotjomela and Hoffmann 2013).

We investigate the effect of invasive alien trees on arthropod assemblages associated with native riparian trees in the CFR, a region heavily impacted by woody IAPs. Riparian ecosystems are among the most endangered CFR habitats, with less than $20 \%$ of their original extent still intact (Nel et al. 2007). Riparian vegetation is used for resting, feeding, reproduction and refuge by both aquatic and terrestrial arthropods, and provides a critical resource base for vertebrates (Gray 1993). One of the most notorious invasive species in the CFR is Acacia mearnsii, which the Working for Water (WfW) invasive plant clearing programme has designated as a top priority for removal (van Wilgen et al. 2008, 2012). Most South African research on A. mearnsii and other IAPs in the Fynbos biome has shown that 
dense stands of invasive acacias can rapidly reduce the abundance and diversity of native plants at the landscape scale (Richardson et al. 1989). Dense stands of IAPs also lead to a decline in soil seed banks of riparian systems (Vosse et al. 2008), increasing the probability of extinctions of native species. In addition, IAPs greatly increase biomass (Milton, 1981), affect fire regimes (Van Wilgen et al. 2008), change nutrient cycles (Witkowski 1991) and reduce arthropod richness (reviewed by Litt et al. 2014).

Clearing of IAPs can lead to recovery of vegetation communities under certain conditions (Blanchard and Holmes 2008) and it can be expected that removal of A. mearnsii from riparian systems would also help restore the high arthropod species diversity that characterizes CFR riparian communities (Samways et al. 2011). Studies have shown that arthropod richness (alpha-diversity) and abundance can recover after restoration efforts on disturbed riparian ecosystems (Williams 1993; Longcore 2003; McCall and Pennings 2012). Removal of invasive Phragmites resulted in the return of dominant native vegetation and the re-establishment of arthropod species assemblages (Gratton and Denno 2005). The effect of clearing of IAPs from CFR riparian ecosystems on riparian arthropod diversity has not yet been assessed.

Although the advantages of the removal of IAPs are apparent, the process itself represents yet another disturbance to river ecosystems. IAP clearing can result in unexpected changes to ecosystem processes that may affect arthropod survival. For example, removal of IAPs alters canopy characteristics, which directly affects the interior environments of ecosystems (i.e., temperature, humidity, and radiation), this, in turn, leads to changes in arthropod richness and abundance (Ziesche and Roth 2008). Apart from microclimate, altered architectural habitat complexity (Schowalter and Crossley 1988) and changes in plant nutritional quality (Fischer et al. 2010), IAP removal may also influence arthropod communities by limiting their dispersal ability by creating isolated patches (Schowalter and Crossley 1988).

The measurement of arthropod species richness (alpha-diversity) and species turnover (betadiversity) under different levels of plant invasions aids our understanding of the effect of management conservation of these systems (Kessler et al. 2009). We test the effect of an invasive alien tree on arthropod alpha- and beta-diversity in riparian ecosystems of the CFR and whether measures of arthropod alpha- and beta-diversity can indicate a trajectory of recovery post-IAP removal. We expected to see differences in arthropod alpha- and betadiversity among areas differing in degree of invasion (near pristine, heavily invaded by $A$. mearnsii and cleared ca. 7 years prior to the commencement of this study), with major differences between the near pristine habitats and those that have been restored reflecting the 
probable time it takes for arthropod assemblages to fully recover after invasion and subsequent mechanical clearing of IAPs.

\section{Materials and methods}

\section{Study area and species}

This study was conducted in the mountain stream and foothill sections of several riparian systems within the Western Cape, South Africa (Fig. 1; Table 1). The selected river reaches are on quartzitic sandstone that is characteristically acidic and low in nutrients and dissolved solids (Day and King 1995) (Table 1). Vegetation is largely shrubby Fynbos and includes a variety of tree taxa that form forest patches (Goldblatt and Manning 2000).

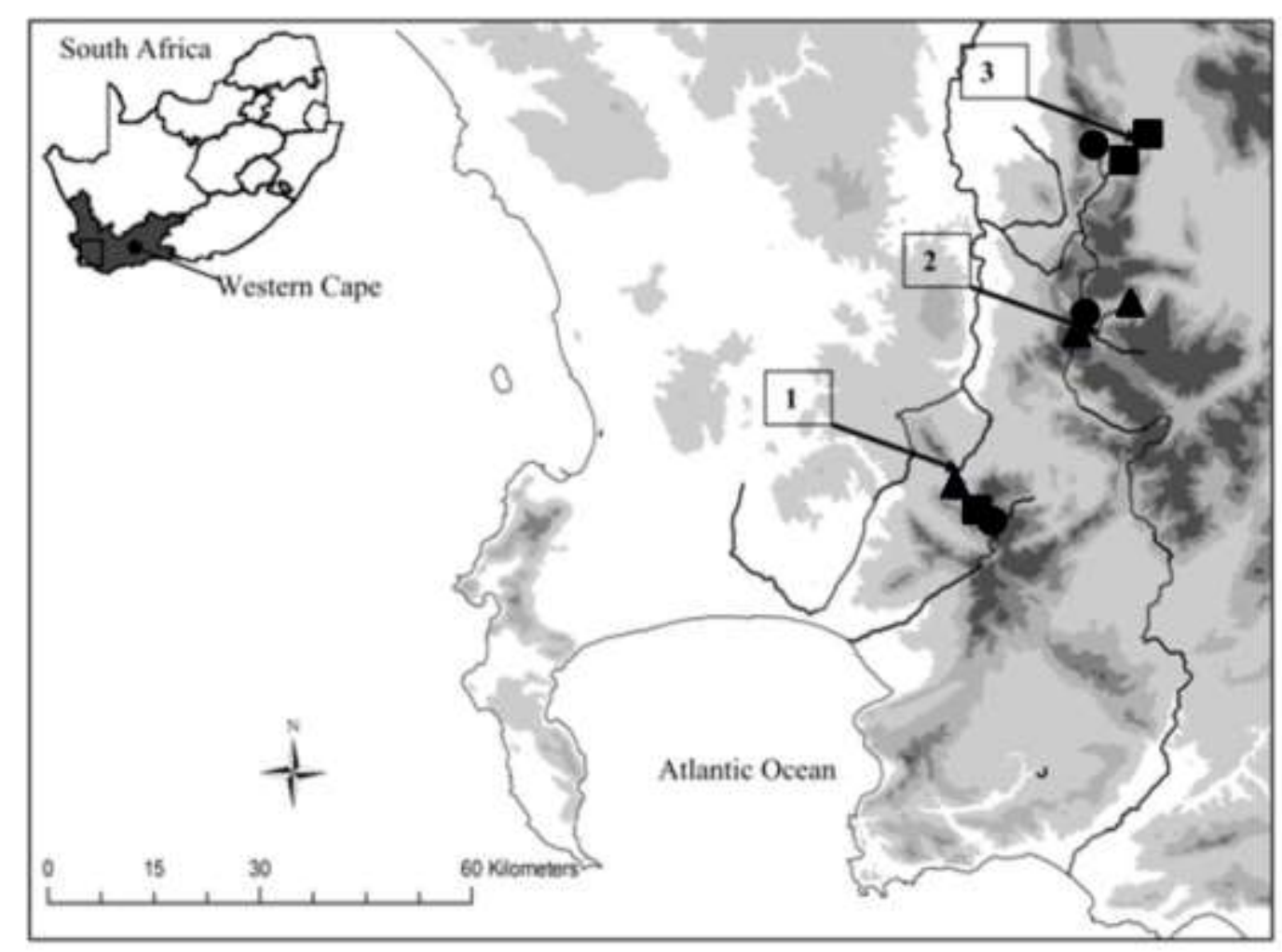

Fig 1: Location of the three Western Cape rivers: $1=$ Dwars, $2=$ Molenaars, and $3=$ Wit and the nine sites (circle: near pristine, square: heavily invaded and triangle: restored) used in this study.

Nine study sites in the three different rivers systems were identified: three near pristine sites (NP) (reference sites), three heavily invaded (HI) sites (predominantly by A. mearnsii), and three restored sites (R) (formerly invaded sites that had been cleared of IAPs more than 7 years prior to this study). Site categorisation into near pristine, heavily invaded was based on 
Table 1: Site-specific information, including the major geomorphological characteristics, site treatment and mean annual rainfall. All the streams are perennial.

\begin{tabular}{|c|c|c|c|c|c|c|c|}
\hline Site & Geology & $\begin{array}{l}\text { Treatment of } \\
\text { Invasion }\end{array}$ & History clearance & Fire History & $\begin{array}{l}\text { Mean annual } \\
\text { rainfall }(\mathrm{mm})\end{array}$ & $\begin{array}{l}\text { Longitudinal } \\
\text { zone }\end{array}$ & Coordinates \\
\hline \multicolumn{8}{|l|}{ Near pristine } \\
\hline Upper Dwars (UD) & $\begin{array}{l}\text { Sandstone } \\
\text { /granite }\end{array}$ & None & None & $\begin{array}{l}\text { No proof of } \\
\text { latest fire }\end{array}$ & 578 & $\begin{array}{l}\text { Mountain } \\
\text { Headwater } \\
\text { stream }\end{array}$ & $\begin{array}{l}33^{\circ} 57^{\prime} 05.54 " \mathrm{~S} \\
18^{\circ} 58^{\prime} 39.22^{\prime \prime} \mathrm{E} \\
\text { Elevation: } 446(\mathrm{~m})\end{array}$ \\
\hline Bains Kloof (BK) & Sandstone & None & None & $\begin{array}{l}\text { No proof of } \\
\text { latest fire }\end{array}$ & 888 & $\begin{array}{l}\text { Mountain } \\
\text { Headwater } \\
\text { stream }\end{array}$ & $\begin{array}{l}33^{\circ} 34^{\prime} 08.49^{\prime \prime} \mathrm{S} \\
19^{\circ} 08^{\prime} 19.03^{\prime \prime} \mathrm{E} \\
\text { Elevation: } 303 \mathrm{~m}\end{array}$ \\
\hline Du toits Kloof (DK) & Sandstone & None & None & $\begin{array}{l}\text { No proof of } \\
\text { latest fire }\end{array}$ & 1468 & Foothill & $\begin{array}{l}33^{\circ} 43^{\prime} 47.41^{\prime \prime} \mathrm{S} \\
19^{\circ} 06^{\prime} 37.06 " \mathrm{E} \\
\text { Elevation: } 472 \mathrm{~m}\end{array}$ \\
\hline \multicolumn{8}{|l|}{ Heavily invaded } \\
\hline Lower Wit (LW) & Sandstone & None & None & 2012 & 833 & Foothill & $\begin{array}{l}33^{\circ} 32^{\prime} 19.56 " \mathrm{~S} ; \\
19^{\circ} 10^{\prime} 51.77^{\prime \prime} \mathrm{E} \\
\text { Elevation: } 243 \mathrm{~m}\end{array}$ \\
\hline Mid Wit (MW) & Sandstone & None & No clear evidence & 2012 & 833 & Foothill & $\begin{array}{l}33^{\circ} 34^{\prime} 06.33^{\prime \prime} \mathrm{S} ; \\
19^{\circ} 08^{\prime} 47.52^{\prime \prime} \mathrm{E} \\
\text { Elevation: } 283 \mathrm{~m}\end{array}$ \\
\hline Mid Dwars (MD) & $\begin{array}{l}\text { Sandstone/ } \\
\text { granite }\end{array}$ & None & No clear evidence & $\begin{array}{l}\text { No proof of } \\
\text { latest fire }\end{array}$ & 578 & $\begin{array}{l}\text { Mountain } \\
\text { stream }\end{array}$ & $\begin{array}{l}33^{\circ} 56^{\prime} 53.36 " \mathrm{~S} ; \\
19^{\circ} 58^{\prime} 11.25^{\prime \prime} \mathrm{E} \\
\text { Elevation: } 400 \mathrm{~m}\end{array}$ \\
\hline \multicolumn{8}{|l|}{ Restored } \\
\hline Upper Molenaars (UM) & Sandstone & $\begin{array}{l}>7 \text { years ago }(A . \\
\text { mearnsii) }\end{array}$ & $\begin{array}{l}\text { Initial treatment: } 2002- \\
2003 \text {. } \\
2 \text { follow-up treatments. } \\
\text { (Fell and remove) }\end{array}$ & 2012 & 889 & Upper Foothill & $\begin{array}{l}33^{\circ} 42^{\prime} 38.56^{\prime \prime} \mathrm{S} ; \\
19^{\circ} 11^{\prime} 49.24^{\prime \prime} \mathrm{E} \\
\text { Elevation: } 335 \mathrm{~m}\end{array}$ \\
\hline Du Toit (DT) & Sandstone & $\begin{array}{l}>7 \text { years ago } \\
(\text { A. mearnsii) }\end{array}$ & $\begin{array}{l}\text { Initial treatment } \\
2002 \text { (Fell and remove) }\end{array}$ & $\begin{array}{l}\text { No proof of } \\
\text { recent fire }\end{array}$ & 1477 & $\begin{array}{l}\text { Upper } \\
\text { Foothill }\end{array}$ & $\begin{array}{l}33^{\circ} 43^{\prime} 34.21^{\prime \prime S} ; \\
19^{\circ} 06^{\prime} 01.02 " \mathrm{E} \\
\text { Elevation: } 544 \mathrm{~m}\end{array}$ \\
\hline Lower Dwars (LD) & Sandstone & $\begin{array}{l}>8 \text { years ago }(A \text {. } \\
\text { mearnsii and } A . \\
\text { longifolia })\end{array}$ & $\begin{array}{l}\text { Initial treatment: } 2002.3 \\
\text { follow-up treatments. } \\
\text { (Fell and remove) }\end{array}$ & $\begin{array}{l}\text { No proof of } \\
\text { recent fire. }\end{array}$ & 578 & $\begin{array}{l}\text { Mountain } \\
\text { stream }\end{array}$ & $\begin{array}{l}33^{\circ} 56^{\prime} 45.74 " \mathrm{~S} ; \\
18^{\circ} 57^{\prime} 57.51^{\prime \prime} \mathrm{E} \\
\text { Elevation: } 385 \mathrm{~m}\end{array}$ \\
\hline
\end{tabular}


visual scoring of Acacia mearnsii cover within two transects measuring $50 \mathrm{~m}$ in length (parallel to the river) and $5 \mathrm{~m}$ in width (perpendicular to the river crossing both wet and dry bank zones). For heavily invaded site A. mearnsii canopy cover $>75 \%$ and near pristine < $5 \%$. For restored sites, site categorisation was based on the Invasive Alien Plants (IAPs) clearing history of the sites. In restored sites, IAPs were felled as close to the base as possible and herbicide was applied to stumps. Potential sites were identified using information obtained from previous studies (Blanchard and Holmes 2008) and confirmed by discussions with conservation authority managers (CapeNature), members of WfW and private landowners.

For the purposes of this study, two tree species endemic to Fynbos riparian zones, Brabejum stellatifolium (L.) (Proteaceae) and Metrosideros angustifolia (L.) (Myrtaceae) were selected. These trees are naturally confined to the Fynbos (Thuiller et al. 2006) where they prefer moist areas and therefore commonly occur along streams (Mucina and Rutherford 2006). These tree species are abundant and important components of riparian habitats and considered key species in south-western Cape Mediterranean-type riparian systems (Galatowitsch and Richardson 2005). In addition to these two native species, the woody invasive alien species Acacia mearnsii DeWild (L.) (Fabaceae) that commonly invades habitats dominated by $B$. stellatifolium and M. angustifolia was selected. Acacia mearnsii was chosen because it commonly invades habitats dominated by B. stellatifolium and M. angustifolia which were focal native tree species based on their wide distributions with study sites. And also, its seeds germination is usually prompted by disturbances.

\section{Arthropod collection}

As CFR arthropods show substantial seasonal variation (Roets and Pryke 2013), sampling was conducted once during summer (2011), autumn (2011), winter (2012), and spring (2012) and the data from all four seasons were combined for analyses. The sampling was done within two transects measuring $50 \mathrm{~m}$ in length (parallel to the river) and $5 \mathrm{~m}$ in width (perpendicular to the river crossing both wet and dry bank zones). Arthropods associated with the foliage of the three tree species were sampled using a petrol-driven Blow and Vac (Stihl, Germany) suction apparatus (Stewart and Wright 1995). Five individuals of each of the three tree taxa of similar height and stem diameter were selected at random at each site and arthropods collected from their crowns by inserting tips of branches into the nozzle for 30s. This process was repeated 70 times on different branches for each individual tree. Catches per individual tree were kept separate. Collected arthropods were transferred to re-sealable plastic bags, stored at $-20^{\circ} \mathrm{C}$, and later assigned to morphospecies and taxonomic order (Oliver and Beattie 1996). 
Reference material was stored in $70 \%$ ethanol and is held at the University Stellenbosch Insect Collection (USEC), Stellenbosch, South Africa.

\section{Statistical analyses}

A non-parametric richness estimator was selected, to establish sampling representativity because most arthropod assemblages normally have large number of rare species (Hortal et al. 2006). The Chao 2 estimator was used as it is considered to be the least biased and most precise estimator when working with small sample sizes (Walther and Morand 1998). Values were calculated using EstimateS (Colwell 2009).

Arthropod alpha-diversity ( $\alpha$ ) (or species richness) for heavily invaded, restored and near pristine riparian plant invasions was compared using Generalised Linear Models (GLMs). These variables were fitted to a Poisson distribution model with a log-link function using generalised estimating equations (Zuur et al. 2010) in Proc Genmod of SAS 9.1 (SAS Institute Inc., Cary, USA). The Poisson distribution type was selected to minimize the deviance statistic (Johnson et al. 2006). Test statistics were calculated using the penalised quasilikelihood technique, as variances showed no over-dispersion (Bolker et al. 2008). Separate analyses were run for the three host tree species, sites within each plant invasions type, as well as for the eight most species rich arthropod taxonomic groups (Araneae, Coleoptera, Diptera, Hemiptera, Hymenoptera, Lepidoptera, Ants, and Orthoptera). Significant differences under this model are reported where $P \leq 0.05$.

Two measures of beta-diversity were assessed in this study: (i) $\beta 1=$ species turnover among sites of the same plant invasions (Anderson 2006) and (ii) $\beta 2=$ assemblage compositional changes between sites with different plant invasions (Anderson 2006; Pryke et al. 2013). Species turnover among sites of the same plant invasions $(\beta 1)$ was calculated using a resemblance matrix based on the Jaccard measure. The Jaccard dissimilarity measure uses only compositional (presence/absence) information and is directly interpretable as the percentage of unshared species among samples (Terlizzi et al. 2009). To determine the variability in species composition within the study sites, the Permutational Analysis of Multivariate Dispersions (PERMDISP) routine in the Permutational Multivariate Analysis of Variance (PERMANOVA+) extension in PRIMER 6 was conducted. PERMDISP ( $\beta 1$ diversity) determines the mean distance of samples to the geometric centre (centroid) of each predefined group (e.g. arthropods associated with A. mearnsii from near pristine sites) in three dimensional space (Anderson 2006). This allows for comparisons between the mean distances to various centroids (e.g. arthropods associated with A. mearnsii from near pristine, restored 
and heavily invaded sites respectively) using ANOVA to determine F- and p-values (Anderson 2006) and allows for pair-wise testing. These analyses were performed in PRIMER 6 (PRIMER-E 2008) with 9,999 permutations (Anderson 2006).

Compositional differences across different plant invasion status (near pristine, heavily invaded and restored) and sites within each plant invasion status ( $\beta 2)$ (Anderson 2006) were compared using PERMANOVA+ in PRIMER 6. The F and p- values for the main test (as well as $\mathrm{t}$ values for pair-wise differences) for similarity of the eight taxonomic groups listed above between each plant invasion type and the three host trees were calculated using 9,999 permutations. Hierarchical agglomerative clustering analyses were performed using BrayCurtis similarity (Bray and Curtis 1957) after fourth-root transformation of data to reduce the influence of common species (Anderson 2001). Results were visually represented using Principal Coordinates Ordination (PCO) plots (Clarke 1993) in PRIMER 6. Diversity indices were compared for all tree taxa combined, for each individual tree species and for the eight most species rich arthropod taxonomic groups.

\section{Results}

\section{Arthropod alpha-diversity}

A total of 29811 arthropod individuals representing 967 morphospecies from 15 orders were collected. The most abundant orders were the Coleoptera (14,253), Hemiptera (5197), Diptera (3359), Araneae (1734), Hymenoptera (1710) (excluding the Ants, 470), Lepidoptera (237), and Orthoptera (388). The near pristine sites had the highest number of observed and estimated species, while the heavily invaded sites had the lowest number of observed and estimated species (Table 2). The restored sites had intermediate numbers for observed and estimated number of species (Table 2). For M. angustifolia, the estimated numbers of species at heavily invaded sites were similar to those at restored sites (Table 2). For B. stellatifolium and $A$. mearnsii the estimated number of species varied across all the riparian sites with near pristine housing more species for B. stellatifolium and heavily invaded sites for A. mearnsii, than restored sites (Table 2). 
Table 2: Number of collected arthropod species $\left(\mathrm{S}_{\mathrm{obs}}\right)$ and individuals as well as the estimated number of species $($ Chao $2=$ second order Chao estimator) from three tree species at sites that differ in invasive status (near pristine, heavily invaded and restored).

\begin{tabular}{|c|c|c|c|}
\hline Site & $\mathrm{S}_{\mathrm{obs}}$ & Individuals & Chao2( $( \pm \mathrm{SD})$ \\
\hline Overall & 967 & 29811 & $1215(34.1)$ \\
\hline Near pristine & 868 & 9798 & $995.3(44.6)$ \\
\hline B. stellatifolium & 479 & 5234 & $679.5(32.3)$ \\
\hline M. angustifolia & 340 & 2373 & $609.3(59.3)$ \\
\hline A. mearnsii & 346 & 2191 & $488.9(31.8)$ \\
\hline Heavily invaded & 550 & 7667 & $666.9(30.8)$ \\
\hline B. stellatifolium & 250 & 4306 & $453.9(51.1)$ \\
\hline M. angustifolia & 295 & 2012 & $416.5(30.3)$ \\
\hline A. mearnsii & 257 & 1349 & $510.8(65.1)$ \\
\hline Restored & 615 & 12346 & $857.9(45.8)$ \\
\hline B. stellatifolium & 280 & 7976 & $610.5(101.7)$ \\
\hline M. angustifolia & 297 & 2020 & $435.3(33.0)$ \\
\hline A. mearnsii & 338 & 2350 & $486.9(32.4)$ \\
\hline
\end{tabular}

Generalised linear models indicated that for all arthropods from two native tree taxa combined, near pristine sites had significantly higher alpha-diversity than heavily invaded sites with intermediate alpha-diversity at restored sites $\left(\mathrm{F}_{[2,6]}=72.9, \mathrm{p}<0.001\right.$; Table 3$)$. This was also true for all host trees separately $\left(\mathrm{F}_{[2,42]}=72.02, \mathrm{p}<0.001\right.$ for B. stellatifolium; $\mathrm{F}_{[2,42]}$ $=77.1, \mathrm{p}<0.001$ for M. angustifolia $; \mathrm{F}_{[2,42]}=182.8, \mathrm{p}<0.001$ for A. mearnsii; Table 3). Species richness (for all native tree species combined) was highest at near pristine sites for most arthropod orders (excluding the Ants and Lepidoptera), followed by restored sites, with heavily invaded sites usually containing the least number of species (Table 3). However, for most orders the differences in alpha-diversity among degrees of plant invasions for individual tree species were not significant. The ants were more species rich at restored sites, but only significantly so for all native tree taxa combined $\left(\mathrm{F}_{[2,6]}=1.96, \mathrm{p}=0.05\right)$ and for $B$. stellatifolium $\left(\mathrm{F}_{[2,42]}=2.37, \mathrm{p}=0.05\right.$; Table 3$)$. Araneae alpha-diversity was significantly lower at heavily invaded sites for those associated with B. stellatifolium $\left(\mathrm{F}_{[2,6]}=3.19, \mathrm{p}<\right.$ 0.01; Table 3). 
Table 3: Summary results for Generalised Linear Models (Poisson distribution and log-link function) on species richness data for the overall, and eight most species-rich and abundant taxonomic groups.

\begin{tabular}{|c|c|c|c|c|}
\hline \multirow[t]{2}{*}{ Dependent variable } & \multirow[t]{2}{*}{ Overall } & \multicolumn{3}{|c|}{ Tree species } \\
\hline & & B. stellatifolium & M. angustifolia & A. mearnsii \\
\hline \multicolumn{5}{|l|}{ Species Richness } \\
\hline Overall & $\mathrm{NP}>\mathrm{R}>\mathrm{HI}$ & $\mathrm{NP}>\mathrm{R}=\mathrm{HI}$ & $\mathrm{NP}=\mathrm{R} \geq \mathrm{HI}$ & $\mathrm{NP}=\mathrm{R} \geq \mathrm{HI}$ \\
\hline Araneae & $\mathrm{NP}>\mathrm{R}>\mathrm{HI}$ & $\mathrm{NP}>\mathrm{R}>\mathrm{HI}$ & $\mathrm{NP}=\mathrm{R}=\mathrm{HI}$ & $\mathrm{NP}=\mathrm{R}=\mathrm{HI}$ \\
\hline Coleoptera & $\mathrm{NP}>\mathrm{R}=\mathrm{HI}$ & $\mathrm{NP}>\mathrm{R}=\mathrm{HI}$ & $\mathrm{NP}=\mathrm{R}=\mathrm{HI}$ & $\mathrm{NP}=\mathrm{R}=\mathrm{HI}$ \\
\hline Diptera & $\mathrm{NP}>\mathrm{R}>\mathrm{HI}$ & $\mathrm{NP}=\mathrm{HI} \geq \mathrm{R}$ & $\mathrm{NP}=\mathrm{HI}=\mathrm{R}$ & $\mathrm{NP}=\mathrm{HI}=\mathrm{R}$ \\
\hline Hemiptera & $\mathrm{NP}>\mathrm{R}=\mathrm{HI}$ & $\mathrm{NP}>\mathrm{HI}=\mathrm{R}$ & $\mathrm{NP}=\mathrm{R}=\mathrm{HI}$ & $\mathrm{NP}=\mathrm{R}=\mathrm{HI}$ \\
\hline Hymenoptera $^{\mathrm{a}}$ & $\mathrm{NP}>\mathrm{R}=\mathrm{HI}$ & $\mathrm{NP}>\mathrm{R}=\mathrm{HI}$ & $\mathrm{NP}=\mathrm{R}=\mathrm{HI}$ & $\mathrm{R}=\mathrm{NP}=\mathrm{HI}$ \\
\hline Lepidoptera & $\mathrm{NP}=\mathrm{HI}=\mathrm{R}$ & $\mathrm{NP}=\mathrm{R}=\mathrm{HI}$ & $\mathrm{HI}=\mathrm{R}=\mathrm{NP}$ & $\mathrm{R}=\mathrm{NP}=\mathrm{HI}$ \\
\hline Ants & $\mathrm{R}>\mathrm{NP}=\mathrm{HI}$ & $\mathrm{R}>\mathrm{NP}=\mathrm{HI}$ & $\mathrm{R}=\mathrm{NP}=\mathrm{HI}$ & $\mathrm{R}=\mathrm{NP}=\mathrm{HI}$ \\
\hline Orthoptera & $\mathrm{NP}=\mathrm{R}=\mathrm{HI}$ & $\mathrm{NP}=\mathrm{R}=\mathrm{HI}$ & $\mathrm{NP}=\mathrm{R}=\mathrm{HI}$ & $\mathrm{NP}=\mathrm{R}=\mathrm{HI}$ \\
\hline
\end{tabular}

Sites are ordered with those with the highest means on the left and the lowest on the right.

${ }^{\mathrm{a}}$ All members of Hymenoptera except the Ants.

$\mathrm{NP}=$ Near Pristine, $\mathrm{HI}=$ Heavily Invaded, $\mathrm{R}=$ Restored riparian habitat types,

$=$ signifies no significant differences, > signifies that habitats to the left are significantly more species-rich; $\geq$ signifies that the first habitat is significantly more species-rich than the last habitat.

\section{Arthropod species turnover among sites $(\beta 1)$}

When combining all arthropods collected on native hosts, near pristine and restored sites which were statistically similar had significantly higher $\beta 1$-diversity (species turnover among sites) than heavily invaded assemblages $\left(\mathrm{F}_{[2,6]}=8.91, p=0.004\right.$; Table 4). However, the influence of plant invasions of riparian zones on $\beta 1$-diversity was non-significant for most arthropod taxa separately except Coleoptera $\left(\mathrm{F}_{[2,6]}=9.31, \mathrm{p}=0.003\right.$; Table 4). Coleopteran $\beta 1$-diversity was significantly lower at restored sites than at near pristine and heavily invaded sites. $\beta 1$-diversity for the different orders associated with specific tree species varied little among sites with differing plant invasions (Table 4). 
Table 4: Results of tests for $\beta 1$-diversity for host trees using the Jaccard resemblance measure for each tree species using different taxonomic groups.

Tree species

\begin{tabular}{|c|c|c|c|c|}
\hline & Plant invasions & B. stellatifolium & M. angustifolia & A. mearnsii \\
\hline All & $\mathrm{NP}=\mathrm{R} \geq \mathrm{HI}$ & $\mathrm{HI}=\mathrm{R}=\mathrm{NP}$ & $\mathrm{NP}=\mathrm{R}=\mathrm{HI}$ & $\mathrm{NP}=\mathrm{R}=\mathrm{HI}$ \\
\hline Araneae & $\mathrm{HI}=\mathrm{R}=\mathrm{NP}$ & $\mathrm{HI}=\mathrm{R}=\mathrm{NP}$ & $\mathrm{R}=\mathrm{HI}=\mathrm{NP}$ & $\mathrm{R}=\mathrm{NP}=\mathrm{HI}$ \\
\hline Coleoptera & $\mathrm{NP}=\mathrm{HI}>\mathrm{R}$ & $\mathrm{HI}=\mathrm{NP}=\mathrm{R}$ & $\mathrm{NP}=\mathrm{HI}=\mathrm{R}$ & $\mathrm{NP}=\mathrm{R}=\mathrm{HI}$ \\
\hline Diptera & $\mathrm{HI}=\mathrm{R}=\mathrm{NP}$ & $\mathrm{HI}=\mathrm{R}=\mathrm{NP}$ & $\mathrm{HI}=\mathrm{R}=\mathrm{NP}$ & $\mathrm{HI}=\mathrm{NP}=\mathrm{R}$ \\
\hline Hemiptera & $\mathrm{R}=\mathrm{HI}=\mathrm{NP}$ & $\mathrm{HI}=\mathrm{R}=\mathrm{NP}$ & $\mathrm{R}=\mathrm{NP}=\mathrm{HI}$ & $\mathrm{HI}=\mathrm{R}=\mathrm{NP}$ \\
\hline Hymenoptera $^{a}$ & $\mathrm{HI}=\mathrm{R}=\mathrm{NP}$ & $\mathrm{HI}=\mathrm{R}=\mathrm{NP}$ & $\mathrm{R}=\mathrm{NP}=\mathrm{HI}$ & $\mathrm{NP}=\mathrm{R}=\mathrm{HI}$ \\
\hline Lepidoptera & $\mathrm{NP}=\mathrm{R}=\mathrm{HI}$ & $\mathrm{HI}=\mathrm{NP}=\mathrm{R}$ & $\mathrm{NP}=\mathrm{R}=\mathrm{HI}$ & $\mathrm{HI}=\mathrm{R}=\mathrm{NP}$ \\
\hline Ants & $\mathrm{R}=\mathrm{NP}=\mathrm{R}$ & $\mathrm{R}=\mathrm{NP}=\mathrm{HI}$ & $\mathrm{R}=\mathrm{NP}=\mathrm{HI}$ & $\mathrm{HI}=\mathrm{NP}=\mathrm{R}$ \\
\hline Orthoptera & $\mathrm{NP}=\mathrm{R}=\mathrm{HI}$ & $\mathrm{NP}=\mathrm{R}=\mathrm{HI}$ & $\mathrm{NP}=\mathrm{HI}=\mathrm{R}$ & $\mathrm{R}=\mathrm{HI}=\mathrm{NP}$ \\
\hline
\end{tabular}

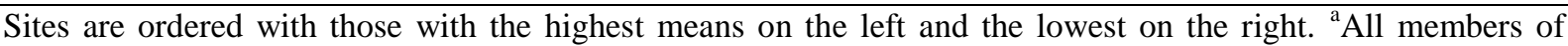
Hymenoptera except the Ants. NP = Near Pristine, HI = Heavily Invaded, $\mathrm{R}=$ Restored riparian habitat types, = signifies no significant differences, > signifies that habitats to the left are significantly more speciesrich/abundant; $\geq$ signifies that the first habitat is significantly more species-rich/ abundant than the last habitat.

Arthropod assemblage composition among sites that differ in plant invasions ( $\beta 2)$

PERMANOVA analyses revealed that plant invasions of riparian habitats significantly influenced arthropod assemblage composition when data from all native trees were combined, with the exception of the Araneae, Coleoptera, Diptera and Lepidoptera (Table 5, Fig 2a). However, nearly all pair-wise comparisons among sites for each arthropod taxon separately (combined tree species data) did not differ significantly except for the Hemiptera, Hymenoptera, Ants and Orthoptera (Table 5).

Riparian plant invasions significantly influenced overall assemblage composition for $B$. stellatifolium and A. mearnsii (Table 5). For B. stellatifolium, pair-wise comparisons indicated that the significant divergence between communities at near pristine- and restored sites drove the overall pattern (Table 5). For M. angustifolia, no significant differences were detected in overall arthropod community assemblages but for a few taxa differences were observed (Table 5). For A. mearnsii no differences were found for pair-wise comparisons among the different plant invasions, but overall plant invasions had a significant influence on arthropod 
Table 5: Arthropod assemblage beta- diversity $(\beta 2)$ from PERMANOVA to determine similarity in the composition of arthropod assemblages among riparian habitats that differ in plant invasions for three tree species and for the eight most species-rich and abundant taxonomic groups.

\begin{tabular}{|c|c|c|c|c|}
\hline & Plant invasions & NP versus HI & NP versus $R$ & HI versus $R$ \\
\hline All & $1.35^{*}$ & 1.33 & 1.11 & 1.04 \\
\hline Araneae & 1.11 & 1.21 & 1.02 & 0.92 \\
\hline Coleoptera & 1.2 & 1.23 & 1.31 & 0.71 \\
\hline Diptera & 1.01 & 1.12 & 1.17 & 0.68 \\
\hline Hemiptera & $2.25 * *$ & $1.48 *$ & $1.46^{*}$ & 1.56 \\
\hline Hymenoptera $^{\mathrm{a}}$ & $2.02 * *$ & $1.51 *$ & $1.46^{*}$ & 1.31 \\
\hline Lepidoptera & 0.74 & 0.84 & 0.84 & 0.89 \\
\hline Ants & $2.09 *$ & $1.80 *$ & $1.48^{*}$ & 0.95 \\
\hline Orthoptera & $2.89 * *$ & $1.94 *$ & $1.64 *$ & $1.47 *$ \\
\hline \multicolumn{5}{|l|}{ B. $\quad$ stellatifolium } \\
\hline Overall & $1.69 * *$ & 1.29 & $1.4^{*}$ & 1.17 \\
\hline Araneae & 1.18 & 1.15 & 1.09 & 1.01 \\
\hline Coleoptera & $2.44 * *$ & 1.53 & $1.79 *$ & 1.33 \\
\hline Diptera & 0.93 & 1.06 & 1.01 & 0.81 \\
\hline Hemiptera & $1.76 * *$ & 1.37 & 1.29 & 1.31 \\
\hline Hymenoptera $^{\mathrm{a}}$ & $1.80 * *$ & 1.36 & 1.36 & 1.31 \\
\hline Lepidoptera & 0.94 & 1.04 & 0.89 & 0.95 \\
\hline Ants & 1.27 & 1.65 & 0.63 & 1.08 \\
\hline Orthoptera & 1.74 & 1.64 & 1.16 & 1.12 \\
\hline \multicolumn{5}{|l|}{ M. angustifolia } \\
\hline Overall & 1.41 & 1.17 & 0.99 & 1.39 \\
\hline Araneae & $1.42 *$ & 1.27 & 1.21 & 1.09 \\
\hline Coleoptera & $1.77 * *$ & $1.44 *$ & $1.35^{*}$ & 1.21 \\
\hline Diptera & $1.33^{*}$ & 1.27 & 1.31 & 0.85 \\
\hline Hemiptera & $1.72 * *$ & 1.24 & $1.43 *$ & 1.26 \\
\hline Hymenoptera $^{\mathrm{a}}$ & 1.65 & 1.44 & 1.22 & 1.18 \\
\hline Lepidoptera & 1.16 & 1.02 & 1.05 & 1.16 \\
\hline Ants & 1.91 & 1.69 & 1.35 & 1.08 \\
\hline Orthoptera & $2.20 *$ & 1.52 & 1.92 & 0.82 \\
\hline \multicolumn{5}{|l|}{ A. mearnsii } \\
\hline Overall & $1.57 *$ & 1.37 & 1.25 & 1.13 \\
\hline Araneae & 1.18 & 1.05 & 1.10 & 1.09 \\
\hline Coleoptera & $1.44^{*}$ & 1.23 & 1.24 & 1.12 \\
\hline Diptera & 1.36 & 1.14 & 1.34 & 1.01 \\
\hline Hemiptera & $1.36^{*}$ & 1.23 & 1.11 & 1.15 \\
\hline Hymenoptera $^{\mathrm{a}}$ & $1.58^{*}$ & 1.35 & 1.27 & 1.14 \\
\hline Lepidoptera & 1.00 & 0.96 & 1.28 & 0.75 \\
\hline Ants & 1.40 & 1.08 & 1.35 & 1.13 \\
\hline Orthoptera & $1.87 *$ & 1.62 & 1.54 & 0.93 \\
\hline
\end{tabular}

Figures represent F- (second column) and t- values (column 3-5), df =8, number of permutations for each analysis $=9,999$.

${ }^{\mathrm{a}}$ All members of Hymenoptera with the exception of Ants. NP $=$ Near Pristine, $\mathrm{HI}=$ Heavily Invaded, $\mathrm{R}=$ Restored riparian habitats, $* P<0.05, * * P<0.01$ 

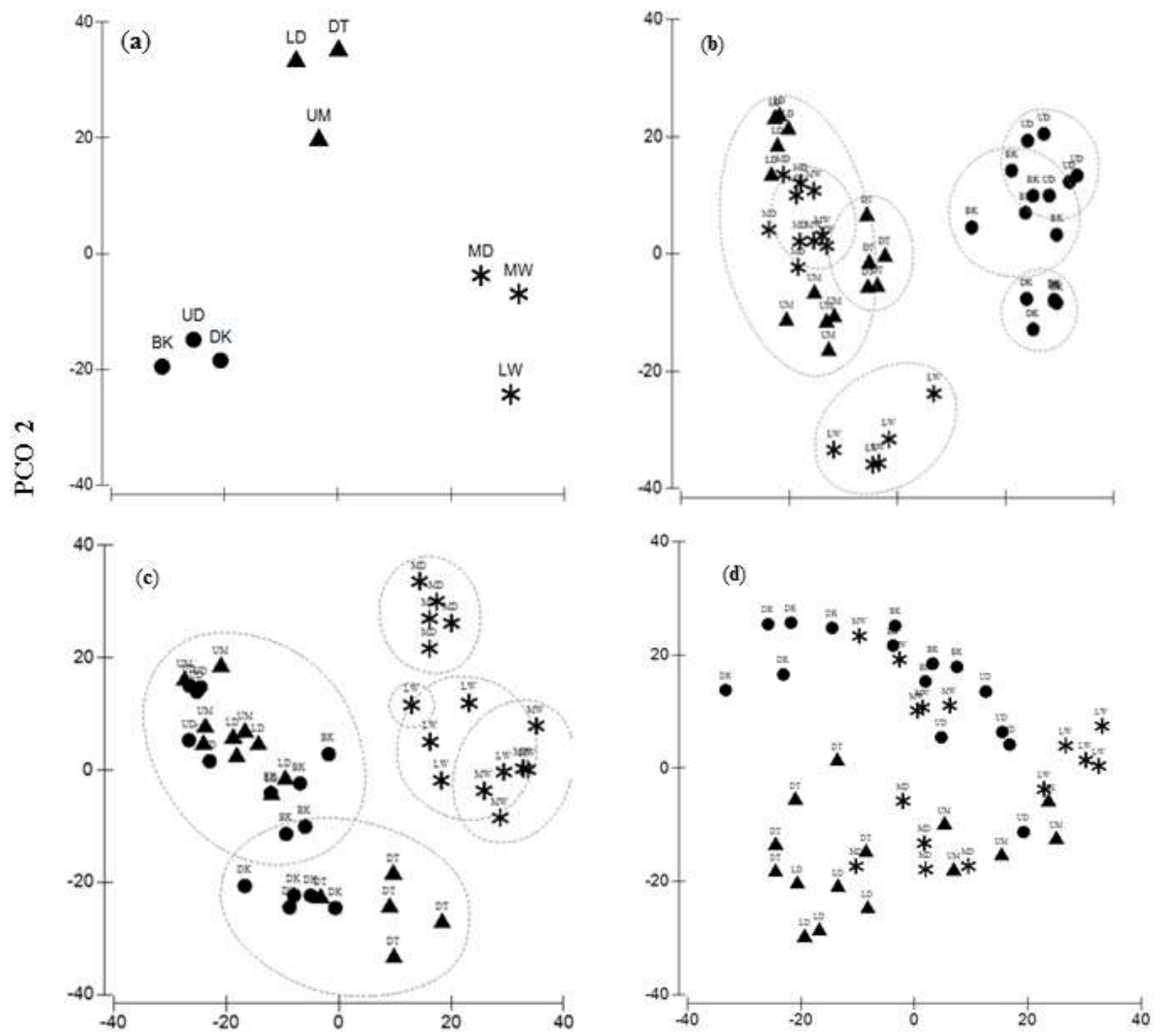

PCO 1

Fig 2: Principal Coordinate Ordination (PCO) plots of arthropod assemblages from near pristine (circle), heavily invaded (star), and restored (triangle) riparian habitats for (a) all arthropods from all host trees combined, (b) arthropods collected from, B. stellatifolium (c) arthropods collected from M. angustifolia and (d) arthropods collected from A. mearnsii. The ellipses represent sampling units which were $25 \%$ similar. UD = Upper Dwars, DK = Du toits Kloof, BK = Bains Kloof, MD = Mid Dwars, LW = Lower Wit, MW = Mid Wit, LD = Lower Dwars, DT $=$ Du Toit, and UM = Upper Molenaars collection sites.

assemblages. Pair-wise comparisons between arthropods from restored and heavily invaded habitats never differed significantly, but comparisons between near pristine and restored, and near pristine and heavily invaded habitats did differ in a few cases (Table 5). Comparisons of sites of the same plant invasion status for individual host tree species also indicated that plant 
Table 6: Main test of arthropod assemblage beta- diversity ( $\beta 2)$ from PERMANOVA to determine similarity in the composition of arthropod assemblages among riparian sites that are similar in plant invasions for three tree species and for the eight most species-rich and abundant taxonomic groups.

\begin{tabular}{|c|c|c|c|}
\hline & Near pristine & Heavily invaded & Restored \\
\hline \multicolumn{4}{|l|}{ B. stellatifolium } \\
\hline Overall & $3.64 * * *$ & $3.39 * * *$ & $3.22 * * *$ \\
\hline Araneae & $2.87 * * *$ & $1.58^{*}$ & $2.83 * * *$ \\
\hline Coleoptera & $4.22 * * *$ & $3.19 * * *$ & $4.16^{* * *}$ \\
\hline Diptera & $3.83 * * *$ & $2.24 * * *$ & $2.89 * * *$ \\
\hline Hemiptera & $2.61 * * *$ & $2.43 * * *$ & $1.51 *$ \\
\hline Hymenoptera $^{a}$ & $3.45^{* * *}$ & $3.40 * * *$ & $3.22 * * *$ \\
\hline Lepidoptera & $1.74 *$ & 1.35 & $1.66^{*}$ \\
\hline Ants & $1.98^{*}$ & $1.81^{*}$ & $1.81^{*}$ \\
\hline Orthoptera & $1.75^{*}$ & 1.49 & 0.87 \\
\hline \multicolumn{4}{|l|}{ M. angustifolia } \\
\hline Overall & $3.24 * * *$ & $2.91 * * *$ & $4.07 * * *$ \\
\hline Araneae & $2.12 * *$ & $1.98 * * *$ & $3.59 * * *$ \\
\hline Coleoptera & $2.97 * * *$ & $3.48 * * *$ & $3.03 * * *$ \\
\hline Diptera & $2.72 * * *$ & $2.28 * * *$ & $3.42 * * *$ \\
\hline Hemiptera & $3.68 * * *$ & $2.17 * * *$ & $4.02 * * *$ \\
\hline Hymenoptera $^{\mathrm{a}}$ & $2.45 * *$ & $4.21 * * *$ & $3.13 * * *$ \\
\hline Lepidoptera & $1.74 *$ & 1.57 & $2.21 * *$ \\
\hline Ants & 1.21 & 1.07 & $5.74 * * *$ \\
\hline Orthoptera & 1.03 & 1.26 & 1.72 \\
\hline \multicolumn{4}{|l|}{ A. mearnsii } \\
\hline Overall & $3.63 * * *$ & $3.89 * * *$ & $3.39 * * *$ \\
\hline Araneae & $1.60 * *$ & $4.85^{* * *}$ & $1.68 * * *$ \\
\hline Coleoptera & $6.45^{* * *}$ & $3.00 * * *$ & $3.44 * * *$ \\
\hline Diptera & $4.73 * * *$ & $4.02 * * *$ & $4.46^{* * *}$ \\
\hline Hemiptera & $2.48 * * *$ & $3.14 * * *$ & $3.31 * * *$ \\
\hline Hymenoptera $^{\mathrm{a}}$ & $4.52 * * *$ & $3.02 * * *$ & $2.81 * * *$ \\
\hline Lepidoptera & $1.83^{*}$ & $1.88 * *$ & 1.39 \\
\hline Ants & 0.95 & $2.15^{* *}$ & 1.38 \\
\hline Orthoptera & 1.10 & 1.61 & 1.07 \\
\hline
\end{tabular}

Figures represent F- values, $\mathrm{df}=44$, number of permutations for each analysis $=9,999$.

${ }^{\mathrm{a}}$ All members of Hymenoptera with the exception of Ants.

$* P<0.05, * * P<0.01, * * * P \leq 0.001$ 
Table 7: Number of common arthropod species (considering only those with more than four individuals collected throughout the study period) that were unique to a specific habitat or tree species, for various assemblages collected from CFR riparian habitats. (Percentage of total in parenthesis).

\begin{tabular}{|c|c|c|c|}
\hline & Near Pristine & Heavily Invaded & Restored \\
\hline All & $295(27.8)$ & $178(16.7)$ & $214(20.1)$ \\
\hline Araneae & $37(3.5)$ & $28(2.6)$ & $50(4.7)$ \\
\hline Coleoptera & $59(6.5)$ & $31(2.9)$ & $41(3.9)$ \\
\hline Diptera & $42(3.9)$ & $19(1.8)$ & $23(2.2)$ \\
\hline Hemiptera & $69(6.5)$ & $29(2.7)$ & $33(3.1)$ \\
\hline Hymenoptera $^{\mathrm{a}}$ & $28(2.6)$ & 17 (1.6) & $19(1.8)$ \\
\hline Lepidoptera & $12(1.1)$ & $8(0.8)$ & $11(1.0)$ \\
\hline Ants & $4(0.4)$ & $2(0.2)$ & $5(0.5)$ \\
\hline Orthoptera & $8(0.8)$ & $3(0.3)$ & $6(0.6)$ \\
\hline \multicolumn{4}{|l|}{ stellatifolium } \\
\hline Overall & $270(39.4)$ & $188(27.4)$ & $219(31.9)$ \\
\hline Araneae & $60(8.8)$ & $27(3.9)$ & $46(6.7)$ \\
\hline Coleoptera & $58(8.5)$ & $50(7.3)$ & $45(6.6)$ \\
\hline Diptera & $42(6.1)$ & $31(4.5)$ & $29(4.2)$ \\
\hline Hemiptera & $57(8.3)$ & $32(4.6)$ & $40(5.8)$ \\
\hline Hymenoptera $^{\mathrm{a}}$ & $22(3.2)$ & $16(2.3)$ & $20(2.9)$ \\
\hline Lepidoptera & $7(1.0)$ & $8(1.2)$ & $10(1.5)$ \\
\hline Ants & $4(0.6)$ & $3(0.4)$ & $7(1.0)$ \\
\hline Orthoptera & $3(0.4)$ & $2(0.3)$ & $1(0.1)$ \\
\hline \multicolumn{4}{|l|}{ M. angustifolia } \\
\hline Overall & $241(38.9)$ & $199(32.1)$ & $220(35.5)$ \\
\hline Araneae & $49(7.9)$ & $32(5.2)$ & $54(8.7)$ \\
\hline Coleoptera & $47(7.6)$ & $49(7.9)$ & $52(8.4)$ \\
\hline Diptera & $34(5.5)$ & $39(6.3)$ & $29(4.7)$ \\
\hline Hemiptera & $56(9.0)$ & $36(5.8)$ & $35(5.7)$ \\
\hline Hymenoptera $^{\mathrm{a}}$ & $32(5.2)$ & $22(3.6)$ & $23(3.7)$ \\
\hline Lepidoptera & $4(0.6)$ & $6(1.0)$ & $3(0.5)$ \\
\hline Ants & $3(0.5)$ & $1(0.2)$ & $5(0.8)$ \\
\hline Orthoptera & $0(0.0)$ & $2(0.3)$ & $4(0.6)$ \\
\hline \multicolumn{4}{|l|}{ A. mearnsii } \\
\hline Overall & $256(38.7)$ & $187(28.3)$ & $262(39.6)$ \\
\hline Araneae & $49(7.4)$ & $31(4.7)$ & $54(8.2)$ \\
\hline Coleoptera & $53(8.0)$ & $35(5.3)$ & $59(8.9)$ \\
\hline Diptera & $35(5.3)$ & $31(4.7)$ & $28(4.2)$ \\
\hline Hemiptera & $49(7.4)$ & $30(4.5)$ & $40(6.1)$ \\
\hline Hymenoptera $^{\mathrm{a}}$ & $29(4.4)$ & $25(3.8)$ & $29(4.4)$ \\
\hline Lepidoptera & $5(0.8)$ & $11(1.7)$ & $13(1.9)$ \\
\hline Ants & $7(1.1)$ & $6(0.9)$ & $3(0.5)$ \\
\hline Orthoptera & $2(0.3)$ & $4(0.6)$ & $5(0.8)$ \\
\hline
\end{tabular}

${ }^{a}$ All members of Hymenoptera with the exception of Ants.

invasions of riparian habitats significantly influenced arthropod assemblage composition, except for a few taxonomic groups (Table 6). 
When considering all arthropods from all two native host tree species combined, the PCO plot showed sites grouped strongly according to plant invasion (Fig 2a). This was also evident when considering arthropods collected from the two native tree taxa respectively, but less so when considering the arthropod communities associated with A. mearnsii (Fig 2d). Near pristine sampling sites for B. stellatifolium were more closely grouped than heavily invaded and restored sampling units that were more intermixed (Fig 2b). For M. angustifolia, heavily invaded units separated out with near pristine and restored sites intermixed (Fig 2c). When considering collection of sites, samples from specific sites tended to group together for all three host trees (Fig 2a).

Considering all arthropods collected for native hosts, near pristine sites had proportionately higher numbers of unique species 295 (27.8\%), higher than either the restored $214(20.1 \%)$ or heavily invaded $178(16.7 \%)$ riparian habitats (Table 7). This was true for all separate tree species. Araneae had proportionately higher numbers of unique species $50(4.7 \%)$ in restored sites, higher than either the near pristine $37(3.5 \%)$ or heavily invaded 28 (2.6\%) riparian habitats (Table 7) for all separate tree species.

\section{Discussion}

Many studies have investigated the effects of invasive alien plants on species richness of arthropods. Although some report no effect on certain arthropod taxa (e.g. Robertson et al. 2011), the vast majority indicate that Invasive Alien Plants (IAPs) have a negative effect on arthropod taxa (e.g. Samways and Moore 1991; Bultman and Dewitt 2008; Samways et al. 2011; Roets and Pryke 2013). The variously invaded riparian habitats compared in this study were found to differ in alpha diversity of arthropods. Near pristine sites had higher species richness than restored sites, with heavily invaded sites housing fewest species for various arthropod taxa except Ants. After removing IAPs these riparian habitats can be recolonised by arthropods, with alpha diversity returning to near pristine levels. Low arthropod species richness in heavily invaded sites was expected given similar results from other studies that have investigated the impacts of invasive alien plants on arthropod populations and communities across a wide variety of habitats; both within South Africa (Samways and Moore 1991; Samways et al. 2011; Roets and Pryke 2013) and elsewhere (Toft et al. 2001; Bultman and Dewitt 2008). However, unlike these studies ours focused on arthropods associated with particular trees rather than arthropods associated with the entire ecosystem. Loss in some arthropod species in invaded sites may therefore be independent of changes in 
plant diversity, vegetation structure and microclimatic conditions (see Litt et al. 2014). These changes would be worth exploring in future studies.

No significant change in species richness of Ants was detected between near pristine and heavily invaded sites. Similarly, French and Major (2001) found no significant differences in the species richness of Ants between areas of South African Fynbos invaded by Acacia saligna and native sites. In contrast to invaded sites, restored sites supported significantly higher species richness of Ants. This suggests that restored sites appear to be benefiting ants, although the mechanisms behind this pattern are unclear. The reduced richness of Araneae in heavily invaded sites could imply reduced predation pressure on folivorous insects (members of Hemiptera and Coleoptera) (Simao et al. 2010), eventually exacerbating folivore damage to native plant species (Halaj and Wise 2001). This decline in Araneae richness in heavily invaded sites suggests that it would be beneficial to quantify damage levels to plants across all plant invasions to explore the possible consequences of altered Araneae richness.

In contrast to Araneae species richness, Lepidoptera and Orthoptera, richness were not affected by plant invasions. This suggests that current management practices in riparian zones in South Africa are not having a major impact on their species richness and that these orders may be less important as indicator groups when assessing IAP status. These findings are similar to Harris et al.'s (2004) argument that invasive plants do not necessarily have to impact biodiversity negatively. In their study, Ulex europaeus (an exotic invasive shrub in New Zealand) supported more insect species of some taxonomic groups than did native Kanuka trees (Kunzea ericoides).

Considering all arthropods together, restored and near pristine sites had much more homogenous arthropod communities as compared to heavily invaded sites, based on PERMDISP results. This suggests that after restoration of a riparian ecosystem, a site is usually recolonised by a community consisting of similar, abundant arthropod taxa. It is possible that, given enough time, rarer arthropod taxa would also recolonise the restored habitats and ultimately increase variability between these areas. Possible reasons for significantly higher $\beta 1$-diversity for arthropods in near pristine as compared to heavily invaded sites are numerous, but may include: (i) higher heterogeneity in both plant species composition and structure (Walz 2011); there is current evidence that diverse habitats support higher biological diversity than monotypic ones, thus allowing more species to coexist (Mlambo et al. 2011), (ii) spatial autocorrelation i.e. sites that are further apart have a tendency to differ drastically in arthropod species composition (Horak 2013). 
Not all arthropods associated with native host taxa reacted similarly to plant invasions and restoration. For example, $\beta 2$-diversity of arthropod communities on B. stellatifolium were fairly similar between restored and invaded sites, while on $M$. angustifolia the arthropod communities from restored sites were more similar to near pristine sites. Restoration success therefore varies considerably when considering the trends associated with individual plant taxa and their respective arthropod communities and they need different lengths of time to regenerate. The reason for this is unclear, but may be due to changes in plant characteristics (e.g. physical structure, leaf chemistry, and host abundance) associated with plant invasion (for example see Lathrop et al. 2003). It is possible that M. angustifolia characteristics that may alter quality of habitats for arthropods for did not change in the presence of IAPs, hence arthropods were quick to recolonise $M$. angustifolia individuals after removal of IAPs. Conversely, IAPs appear to have heavily influenced the characteristics of B. stellatifolium thereby delaying the return of arthropod communities to their original state.

When considering A. mearnsii, arthropod communities, $\beta 2$-diversity varied substantially among different collection sites and among plant invasions. However, plant invasion status of sampling sites had a lesser effect on grouping of communities than it did on collection sites. This can be explained if one considers that most arthropods associated with A. mearnsii are actually associated with the surrounding vegetation rather than A. mearnsii itself (as can be expected from a non-native plant in accordance with the enemy release hypothesis (Wolfe 2002; Siemann and Rogers 2003; van der Colff et al. 2015). Although limited information exists on the arthropod communities of $A$. mearnsii in its invaded range, it is colonised almost exclusively by native arthropods within forestry plantations (Govender 2007, DEA 2009). The arthropod communities associated with A. mearnsii are therefore expected to reflect the general communities associated with the specific sites where it is found.

The results of this study are largely in accordance with other studies (e.g. Wishart et al. (2002), and Samways et al. (2011)) that found that individual rivers of Fynbos bioregions of the Western Cape have specific arthropod communities (i.e. catchment signatures). This is not surprising, given the high spatial variability in Mediterranean-type ecosystems (Caterino 2007). Interestingly, the three Fynbos studies mentioned were limited to aquatic invertebrates while this study focused on terrestrial invertebrates. Thus, the phenomenon of specific river catchment arthropod communities prevails even when the organisms in these systems are not directly dependant on the water itself.

Results further highlight the importance of conserving and maintaining near pristine sites for sustaining overall diversity in riparian habitats as these contain numerous unique species 
(particularly Hemiptera and Coleoptera). Unique species are perceived as important in ecological systems and their preservation is often the ultimate aim of biological monitoring (Lenat and Resh 2001). The recolonisation of restored habitats by particularly rare arthropods will also depend greatly on the availability of nearby suitable habitat. It has previously been demonstrated that fragments of natural habitat in CFR are important for the conservation of many endemic species (Kemper et al. 1999).

To conclude, the above results clearly underscore that alpha and beta-diversity of arthropods are greatly impacted by different plant invasions of riparian habitats. Removal of IAPs appears to benefit species richness of the majority of taxonomic groups. Arthropod beta diversity demonstrated that a change in species composition may be a better measure than alpha diversity to detect shifts in arthropod communities induced by different plant invasion levels of riparian habitats than species richness alone (e.g. Pryke et al. 2013). These changes in community composition may have profound influences on the normal functioning of riparian ecosystems. Restoration success should also be evaluated on a per species basis when considering arthropods associated with foliage as recovery of arthropods on different hosts appears to vary between host species. 


\section{References}

Anderson MJ (2001) A new method for non-parametric multivariate analysis of variance, Austral Ecol 26: 32-46.

Anderson MJ (2006) Distance-based tests for homogeneity of multivariate dispersions. Biometrics 62:245-253.

Beerling DJ, Dawah, HA (1993) Abundance and diversity of invertebrates associated with Fallopia japonica (Houtt. Ronse Decraene) and Impatiens glandulifer (Royle): two alien plant species in the British Isles. Entomologist 112:127-139.

Blanchard R, Holmes, PM (2008) Riparian vegetation recovery after invasive alien tree clearance in the Fynbos Biome. S Afr J Bot 74:421-431.

Bolker BM, Brooks ME, Clark CJ, Geange SW, Poulsen JR, Stevens MHH, White JSS (2008) Generalized linear mixed models: a practical guide for ecology and evolution. Trends Ecol Evol 2:127-135.

Bray JR, Curtis JT (1957) An ordination of the upland forest communities of southern Wisconsin. Ecol Monogr 27:325-349.

Bultman TL, Dewitt DJ (2008) Effect of an invasive ground cover plant on the abundance and diversity of a forest floor spider assemblage. Biol Invasions 10:749-756.

Caterino MS (2007) Species richness and complementarity of beetle faunas in a Mediterranean-type biodiversity hotspot. Biodivers Conserv 6:3993-4006.

Clarke KR (1993) Non-parametric multivariate analyses of changes in community structure. Aust J Ecol 18:117-143.

Clavero M, Garciá-Berthou E (2005) Invasive species are a leading cause of animal extinctions. Trends Ecol Evol 20:110.

Colwell RK (2009) EstimateS: statistical estimation of species richness and shared species from samples (software and user's guide), version 8.2, http://viceroy.eeb.uconn.edu/EstimateS.

Day JA, King JM (1995) Geographical patterns, and their origins, in the dominance of major ions in South African rivers. S Afr J Sci 91:299-306.

Department of Agriculture, Forestry and Fisheries. 2009. State of the forest report.

Fischer DG, Hart SC, Schweitzer JC, Selmants PC, Whitham TG (2010) Soil nitrogen availability varies with plant genetics across diverse river drainages. Plant Soil 331:391400 .

French K, Major RE (2001) Effect of an exotic Acacia (Fabaceae) on ant assemblages in South African fynbos. Austral Ecol 26:303-310. 
Galatowitsch S, Richardson DM (2005) Riparian scrub recovery after clearing of invasive alien trees in headwater streams of the Western Cape, South Africa. Biol Conserv 12:509-521.

Goldblatt P, Manning JC (2000) Cape Plants: a conspectus of the Cape Flora of South Africa. Strelitzia 7:1-743.

Govender P (2007) Status of seedling establishment pest of Acacia mearnsii De Wild. (Mimosaceae) in South Africa. S Afr J Sci 103:141-147.

Gratton C, Denno RF (2005) Restoration of arthropod assemblages in a Spartina salt marsh following removal of the invasive plant Phragmites australis. Restoration Ecol 13:358372.

Gray LJ (1993) Response of insectivorous birds to emerging aquatic insects in riparian habitats of a tallgrass prairie stream. Am Midl Nat 129:288-300.

Halaj J, Wise DH (2001) Terrestrial trophic cascades: how much do they trickle? Am Nat 157:262-281.

Harris RJ, Toft RJ, Dugdale JS, Williams PA, Rees JS (2004) Insect assemblages in a native (kanuka - Kunzea ericoides) and an invasive (gorse - Ulex europaeus) shrubland. New Zeal J Ecol 28:35-47.

Herrera AM, Dudley TL (2003) Reduction of riparian arthropod abundance and diversity as a consequence of giant reed (Arundo donax) invasion. Biol Invasions 5:167-177.

Horak J (2013) Effect of site level environmental variables, spatial autocorrelation and sampling intensity on arthropod communities in an ancient temperate lowland woodland area. PloS ONE 8: e81541.

Hortal J, Borges PAV, Gaspar C (2006) Evaluating the performance of species richness estimators: sensitivity to sample grain size. J Anim Ecol 75:274-287.

Johnson MTJ, Lajeunesse MJ, Agrawal AA (2006) Additive and interactive effects of plant genotypic diversity on arthropod communities and plant fitness. Ecol Lett 9:24-34.

Kemper J, Cowling R, Richardson DM (1999) Fragmentation of South African renosterveld shrublands: Effects on plant community structure and conservation implications. Biol Conserv 90:103-111.

Kessler M, Abrahamczyk S, Bos M, Buchori D, Putra DD, Gradstein SR, Höhn P, Kluge J, Orend F, Pitopang R, Saleh S, Schulze CH, Sporn, SG, Steffan-Dewenter I, Tjitrosoedirdjo SS, Tscharntke T (2009) Alpha and beta diversity of plants and animals along a tropical land-use gradient. Ecol Appl 19:2142-2156. 
Lathrop RG, Windham L, Montesano P (2003) Does Phragmites expansion alter the structure and function of marsh landscapes? Patterns and processes revisited. Estuaries 26:423435.

Lenat DR, Resh VH (2001) Taxonomy and stream ecology - The benefits of genus- and species level identification. J N Am Benthol Soc 20:287-298.

Le Maitre DC, Richardson DM, Chapman RA (2004) Alien plant invasions in South Africa: case studies of the costs and benefits of management. Forest Ecol Manag 160:143-159.

Litt AR, Cord EE, Fulbright TE, Schuster GL (2014) Effects of invasive plants on arthropods. Conserv Biol 28:1532-1549.

Longcore T (2003) Terrestrial arthropods as indicators of ecological restoration success in coastal sage scrub (California, U.S.A.). Restoration Ecol 11:397-409.

Magoba RNN, Samways MJ (2012) Comparative footprint of alien, agricultural and restored vegetation on surface-active arthropods. Biol Invasions 14:165-177.

McCall BD, Pennings SC (2012) Disturbance and recovery of salt marsh arthropod communities following BP deepwater horizon oil spill. PLoS ONE, 7:1-7.

Milton SJ (1981) Above-ground biomass of Australian acacias in the southern Cape, South Africa. S Afr J Bot 47:701-716.

Mlambo MC, Bird MS, Reed CC, Day JA (2011) Diversity patterns of temporary wetland macroinvertebrate assemblages in the south-western Cape, South Africa. Afr J Aquat Sci 36:299-308.

Mokotjomela TM, Hoffmann JH (2013) Removal of post-dispersed seeds in Acacia cyclops thickets under biological control in South Africa. S Afr J Bot 88:260-264.

Mucina L, Rutherford MC (2006) The vegetation of South Africa, Lesotho and Swaziland. Strelitzia 19. South African National Biodiversity Institute, Pretoria.

Nel JL, Roux DJ, Maree G, Kleynhans CJ, Moolman J, Reyers B, Rouget M, Cowling RM (2007) Rivers in peril inside and outside protected areas: a systematic approach to conservation assessment of river ecosystems. Diversity and Distributions 13:341-352.

Oliver I, Beattie AJ (1996) Invertebrate morphospecies as surrogates for species: a case study. Conserv Biol 10:99-109.

PRIMER-E, 2008. PERMANOVA and PRIMER 6. PRIMER-E, Ivybridge, United Kingdom.

Pryke JS, Roets F, Samways MJ (2013) Importance of habitat heterogeneity in remnant patches for conserving dung beetles. J Insect Conserv 22:2857-2873.

Richardson DM, Macdonald IAW, Forsyth GG (1989) Reductions in plant species richness under stands of alien trees and shrubs in the Fynbos biome. J S Afr Fores 149:1-8. 
Robertson MP, Harris KR, Coetzee JL, Foxcroft L, Dippenaar-Schoeman AS, van Rensburg BJ (2011) Assessing the local scale impacts of Opuntia stricta (Cactacea) invasion on beetle and spider diversity in the Kruger National Park, South Africa. Afr Zool 46:205223.

Roets F, Pryke JS (2013) The rehabilitation value of a small culturally significant island based on the arthropod natural capital. J Insect Conserv 17:53-65.

Sala OE, Stuart Chapin III F, Armesto JJ, Berlow E, Bloomfield J, Dirzo R, Huber-Sanwald E, Huenneke LF, Jackson RB, Kinzig A, Leemans R, Lodge DM, Mooney HA, Oesterheld M, LeRoy-Poff N, Sykes MT, Walker BH, Walker M, Wall DH (2000) Global biodiversity scenarios for the year 2100. Science 287:1770-1774.

Samways MJ, Moore SD (1991) Influence of exotic conifer patches on grasshopper (Orthoptera) assemblages in a grassland matrix at a recreational resort, Natal, South Africa. Biol Conserv 57:117-137.

Samways MJ, Sharratt NJ, Simaika JP (2011) Effect of alien riparian vegetation and its removal on a highly endemic river macroinvertebrate community. Biol Invasions 13:1305-1324.

Schowalter TD, Crossley DAJ (1988) Canopy arthropods and their response to forest disturbance. In: Swank WT, Crossley Jr D. (eds) Forest hydrology and ecology at Coweeta. Springer-Verlag, New York, pp 207-218.

Siemann E, Rogers WE (2003) Herbivory, disease, recruitment limitation, and success of alien and native tree species. Ecology 84:1489-505.

Simao MCM, Flory SL, Rudgers JA (2010) Experimental plant invasion reduces arthropod abundance and richness across multiple trophic levels. Oikos 119:1553-1562.

Slobodchikoff CN, Doven JT (1977) Effects of Ammophila arenaria on sand dune arthropod communities. Ecology 58:1171-1175.

Stewart AJA, Wright AF (1995) A new inexpensive suction apparatus for sampling arthropods in grassland. Ecol Entomol 20:98-102.

Tallamy DW (2004) Do alien plants reduce insect bio-mass? Conserv Biol 18:1689-1692.

Terlizzi A, Anderson M, Bevilacqua S, Fraschetti S, Włodarska-Kowalczuk M, Ellingsen KE (2009) Beta diversity and taxonomic sufficiency: Do higher-level taxa reflect heterogeneity in species composition? Diversity and Distributions 15:450-458.

Thuiller W, Richardson DM, Rouget M, Procheş Ş, Wilson JRU (2006) Interactions between environment, species traits and human uses describe patterns of plant invasion. Ecology, 87:1755-69. 
Toft RJ, Harris RJ, Williams PA (2001) Impacts of the weed Tradescantia fluminensis on insect communities in fragmented forests in New Zealand. Biol Conserv 102:31-46.

van der Colff D, Dreyer LL, Valentine A, Roets F (2015) Invasive plants species may serve as a biological corridor for the invertebrate fauna of naturally isolated hosts. J Insect Conserv 19:863-875.

van Wilgen BW, Reyers B, Le Maitre DC, Richardson DM, Schonegevel L (2008) A biomescale assessment of the impact of invasive alien plants on ecosystem services in South Africa. J Environ Manage 89:336-349.

van Wilgen BW, Forsyth GC, Le Maitre DC, Wannenburgh A, Kotzé JDF, van den Berg E, Henderson L (2012) An assessment of the effectiveness of a large, national-scale invasive alien plant control strategy in South Africa. Biol Conserv 148:28-38.

Vosse S, Esler KJ, Richardson DM, Holmes PM (2008) Can riparian seed banks initiate restoration after alien plant invasion? Evidence from the Western Cape, South Africa. S Afr J Bot 74:432-44.

Walther BA, Morand S (1998) Comparative performance of species richness estimation methods. Parasitology 116:395-405.

Walz U (2011) Landscape structure, landscape metrics and biodiversity. Living Reviews in landscape research 5:3.

Williams KS (1993) Use of terrestrial arthropods to evaluate restored riparian woodlands. Restoration Ecol 1:107-116.

Wishart MJ, Davies BR, Stewart BA, Hughes JM (2002) Examining catchments as functional units for the conservation of Riverine Biota and maintenance of biodiversity. WRC report no. 975/1/02. Water Research Commission, Pretoria, South Africa.

Witkowski ETF (1991) Effects of invasive alien acacias on nutrient cycling in the coastal lowlands of the Cape Fynbos. J Appl Ecol 28:1-15.

Wolfe LM (2002) Why alien invaders succeed: support for the escape-from-enemy hypothesis. Am Nat 160:705-11.

Ziesche TM, Roth M (2008) Influence of environmental parameters on small-scale distribution of soil-dwelling spiders in forests: what makes the difference, tree species or microhabitat? Forest Ecol Manag 255:738-752.

Zuur AF, Elena NI, Elphick CS (2010) A protocol for data exploration to avoid common statistical problems. Methods Ecol Evol 1:1-14. 